\title{
ULTRASONIC PHYTOSANITATION OF PINEWOOD NEMATODE INFECTED WOOD
}

\author{
Amir Sohi ${ }^{1}$, Adnan Uzunovic ${ }^{2}$, Stavros Avramidis ${ }^{1, \$}$
}

\begin{abstract}
Pinewood nematode (Bursaphelenchus xylophilus) mortality was investigated after ultrasonic treatment at 20 and $40 \mathrm{kHz}$ frequency. Experiments were conducted with infected small wood specimens that were ultrasonically treated for 1, 3,5 and 7 hours and two variable temperature conditions, namely, a gradually increasing from ambient to a maximum of $70^{\circ} \mathrm{C}$ and a decreasing from ambient to a minimum of $5^{\circ} \mathrm{C}$. The results revealed that the ultrasonic treatment itself had no significant effect on the nematode mortality at the $5^{\circ} \mathrm{C}$ level, while at the $70^{\circ} \mathrm{C}$ level, considerable nematode mortality was observed in short time periods and at 7 hours of sonic exposure it reached $100 \%$. Therefore, certain combinations of timing and frequency of ultrasonic waves and produced heat can be effective in killing pinewood nematodes thus resulting in phytosanitized wood.
\end{abstract}

Keywords: Bursaphelenchus xylophilus, Leptographium terebrantis, Leptographium longiclavatum, Ophiostoma montium, Ophiostoma clavigerum, Pinus contorta.

\section{INTRODUCTION}

Many non-native organisms are transported and dispersed through the human-mediated trade of goods. Non-native organisms may compete directly with native species resulting in threatening biodiversity, affecting native ecology, and possibly causing substantial economic losses. Forest products are favored food sources and host materials for varying types of organisms; often becoming the medium of accidental transportation from one geographic location to another for forest-destroying insects and microorganisms. Because of that, there is increasing vigilance by many countries in protecting their borders from pest entry (Anonymous 2009a).

Chemical based phytosanitation methods (i.e. fumigation), and especially treatments with methyl bromide $(\mathrm{MeBr})$ have been the most widely used for wood and other commodities. Apart from using the classic phytosanitation method of heating, fumigation with $\mathrm{MeBr}$ is the only approved treatment for wood packaging according to ISPM 15 (Anonymous 2002, 2009c). Because MeBr depletes the stratospheric ozone layer, the amount of $\mathrm{MeBr}$ produced and imported was reduced significantly leading to its complete phase out. As per the Montreal Protocol on Substances that Deplete the Ozone Layer, it is only allowed under the Quarantine and Preshipment (QPS) exemption to eliminate quarantine pests, and the Critical Use Exemption designed for agricultural users with no technically or economically feasible alternatives (Anonymous 2009b). Since no alternative fumigant has yet to be developed, heat is the only phytosanitary treatment currently available to the wood and packaging industry. Conductive/ convective heating is time and energy consuming process and in some cases, its drying effect could be detrimental to product quality. Thus, there is significant need for new non-chemical based alternative treatments. Dielectric heating both a radio and microwave frequency levels was tested with positive results for green logs, timbers and packaging materials thus leading to its adoption as substitute treatment (Lazarescu et al. 2010, Hoover et al. 2010, Uzunovic et al. 2013, Lazarescu et al. 2015).

\footnotetext{
${ }^{1}$ University of British Columbia, Department of Wood Science, Vancouver, BC, Canada.

${ }^{2} \mathrm{FP}$ Innovations, Vancouver, BC, Canada.

•Corresponding author: stavros.avramidis@ubc.ca

Received: 19.06.2015 Accepted: 31.10.2015
} 
Environmentally, the generation and propagation of sound is relatively easy and safe so, high frequency sound waves have found many applications (Bucur 2006) including improving permeability and preservative penetration in wood (Tanaka et al.2010) and as a suitable technique for pasteurizing and killing bacteria in foodstuff (Ercan and Soysal 2013). Ultrasound (frequency higher than 15-20 $\mathrm{kHz}$ ) is inaudible to the human ear and is known to cause both inactivation and, at higher acoustic power inputs, disruption of microbial cells. The mechanism of cell disruption is probably linked to cavitation phenomena associated with ultrasonication (McClements 1995). At sufficiently high acoustic power inputs, microbubbles form at various nucleation sites in the fluid. These bubbles grow during the rarefaction phase of the sound wave and then, in the compression phase, the bubbles are compressed to a minimum radius where they collapse releasing a violent shock wave which propagates through the medium. This formation, growth and collapse of gas and vapor bubbles owing to the action of intense sound waves is termed cavitation. In the collapse phase of cavitation, a large quantity of sonic is converted to mechanical energy in the form of elastic waves where heat is also released.

Research results from foodstuff ultrasonic treatment revealed that the produced heat can be useful for pasteurization (Crosby 1982, Sala et al. 1995, McClements 1995, Kim et al. 1999, Salleh-Mack and Roberts 2007, Ercan and Soysal 2013). Taylor et al. (2011) investigated the potential for high intensity ultrasound for the phytosanitation of wood products for decay, mold and termites. They concluded that the ultrasonic treatment was not effective in killing these organisms in wood and did not appear to have the potential to be a stand-alone wood pasteurization treatment.

Given that there is insufficient research on using ultrasound as a means of exterminating wood pests in general and nil on nematodes in particular, the aim of this short study was to explore the eradicating effect on the latter and possibly develop a phytosanitation protocol using ultrasonic energy. The pinewood nematode (Bursaphelenchus xylophilus (Steiner \& Buhrer) Nickle) was selected as a choice test pest since it is perceived a major forest pest requiring reliable phytosanitary treatments.

\section{MATERIALS AND METHODS}

Eighty lodgepole pine (Pinus contorta subsp. latifolia Engelmann) sapwood samples of $20 \times 15 \times 3$ $\mathrm{mm}$ in dimensions were prepared from freshly cut green wood with no visible defects. These samples were wrapped with two layers of polyethylene sheet and were sterilized with $25 \mathrm{kGy}$ of ionizing irradiation. The samples were inoculated with a hyphae/spore mixture of fungi (Leptographium terebrantis, Leptographium longiclavatum, Ophiostoma montium and Ophiostoma clavigerum) grown for two weeks on $1 \%$ malt extract agar. These fungi are regularly isolated from blue stained lodgepole pine especially when attacked by the mountain pine beetle (Dendroctonus ponderosae Hopkins) where nematodes are also encountered and the fungi are their food source. The wood samples were then placed in one liter sterile Mason jars lined with water soaked blotting paper and rubber sink matting. The jars were capped with a thick felt fabric and were covered by aluminum foil to prevent contamination and moisture loss, while allowing for aeration. All wood samples were incubated at $25^{\circ} \mathrm{C}$ for 14 days allowing test fungi to colonize the substrate, after which each sample was inoculated aseptically with 1000 nematodes from a nematode rich slurry in sterile water, delivered in a volume of $100 \mu \mathrm{l}$ (Hoover et al. 2010).

The tests had three replicates in each assessment along with three control samples for each evaluation. During ultrasonic treatment, every sample was fixed on a holder and then submerged in a container filled with water. Treatments were carried out with a horn (Fisher Scientific Sonic Dismembrator F550) that operated at $20 \mathrm{kHz}$ frequency and 200 watts power and in an ultrasonic cleaner (Branson 3210) at 40kHz frequency and 320 watts power.

Since ultrasonic energy produces heat thus increasing the temperature of the water bath with time, in order to decouple the ultrasonic energy effect on nematode mortality from that of the generated heat, two heating regimes were used: one gradually increasing to a maximum of $70^{\circ} \mathrm{C}\left(\mathrm{T}_{\mathrm{A}}\right)$ and one maintained below $20^{\circ} \mathrm{C}$ that gradually dropped to $5^{\circ} \mathrm{C}\left(\mathrm{T}_{\mathrm{B}}\right)$. The latter tests were done while using a copper tube with running water that was submerged in the water tank and was connected to tap water. 
Three different times of exposure (1, 3 and 5 hours) to ultrasonic radiation were tested to assess if they had an effect on nematode mortality. An extra time step of 7-hour exposure to the acoustic horn alone was also included in this work.

Upon completion of the treatments, nematode mortality assessment was carried out according to the protocol described by Hoover et al. (2010). Wood samples were chopped in thin slices after treatment, placed in Baermann funnels, and assessed after 24 hours under a field microscope for live nematodes.

\section{RESULTS AND DISCUSSION}

The conditions of treatments are listed in table 1. Although in our study two ultrasonic instrument setups were used with different frequencies and power levels, the results of the tests were nearly the same. This means that there was no specific difference between the effects of the ultrasonic energy on eradicating pinewood nematodes at $20 \mathrm{kHz} / 200$ watts and $40 \mathrm{kHz} / 320$ watts combinations.

Table 1. The ultrasonic treatment conditions of nematode infested wood specimens.

\begin{tabular}{|c|c|c|c|c|c|c|c|}
\hline \multicolumn{8}{|c|}{ Ultrasonic cleaner } \\
\hline Temperature & \multicolumn{4}{|c|}{ Gradually increasing } & \multicolumn{3}{|c|}{ Low level decreasing } \\
\hline Time & $1(\mathrm{~h})$ & $3(\mathrm{~h})$ & \multicolumn{2}{|c|}{$5(\mathrm{~h})$} & $1(\mathrm{~h})$ & $3(\mathrm{~h})$ & $5(\mathrm{~h})$ \\
\hline Replicates & 3 & 3 & \multicolumn{2}{|c|}{3} & 3 & 3 & 3 \\
\hline $\begin{array}{l}\text { Initial Temperature of the } \\
\text { water }\left({ }^{\circ} \mathrm{C}\right)\end{array}$ & 23 & 23 & \multicolumn{2}{|c|}{23} & 23 & 23 & 23 \\
\hline $\begin{array}{c}\text { Final Temperature of the } \\
\text { water }\left({ }^{\circ} \mathrm{C}\right)\end{array}$ & 33 & 45 & \multicolumn{2}{|c|}{57} & 17 & 10 & 5 \\
\hline Frequency $(\mathrm{kHz})$ & 40 & 40 & \multicolumn{2}{|c|}{40} & 40 & 40 & 40 \\
\hline Power (watts) & 320 & 320 & \multicolumn{2}{|c|}{320} & 320 & 320 & 320 \\
\hline \multicolumn{8}{|c|}{ Ultrasonic horn } \\
\hline Temperature & \multicolumn{4}{|c|}{ Gradually increasing } & \multicolumn{3}{|c|}{ Low level decreasing } \\
\hline Time & $1(\mathrm{~h})$ & $3(\mathrm{~h})$ & $5(\mathrm{~h})$ & $7(\mathrm{~h})$ & $1(\mathrm{~h})$ & $3(\mathrm{~h})$ & $5(\mathrm{~h})$ \\
\hline Replicates & 3 & 3 & 3 & 3 & 3 & 3 & 3 \\
\hline $\begin{array}{l}\text { Initial Temperature of the } \\
\text { water }\left({ }^{\circ} \mathrm{C}\right)\end{array}$ & 23 & 23 & 23 & 23 & 23 & 23 & 23 \\
\hline $\begin{array}{c}\text { Final Temperature of the } \\
\text { water }\left({ }^{\circ} \mathrm{C}\right)\end{array}$ & 30 & 43 & 56 & 70 & 17 & 12 & 5,5 \\
\hline Frequency $(\mathrm{kHz})$ & 20 & 20 & 20 & 20 & 20 & 20 & 20 \\
\hline Power (watts) & 200 & 200 & 200 & 200 & 200 & 200 & 200 \\
\hline
\end{tabular}

Figures 1 and 2 show the water bath temperature change against time during treatments. It is clear from the graphs that ultrasonic energy gently and raised water/sample temperature at an approximately $6,1^{\circ} \mathrm{C}$ per hour rate. 


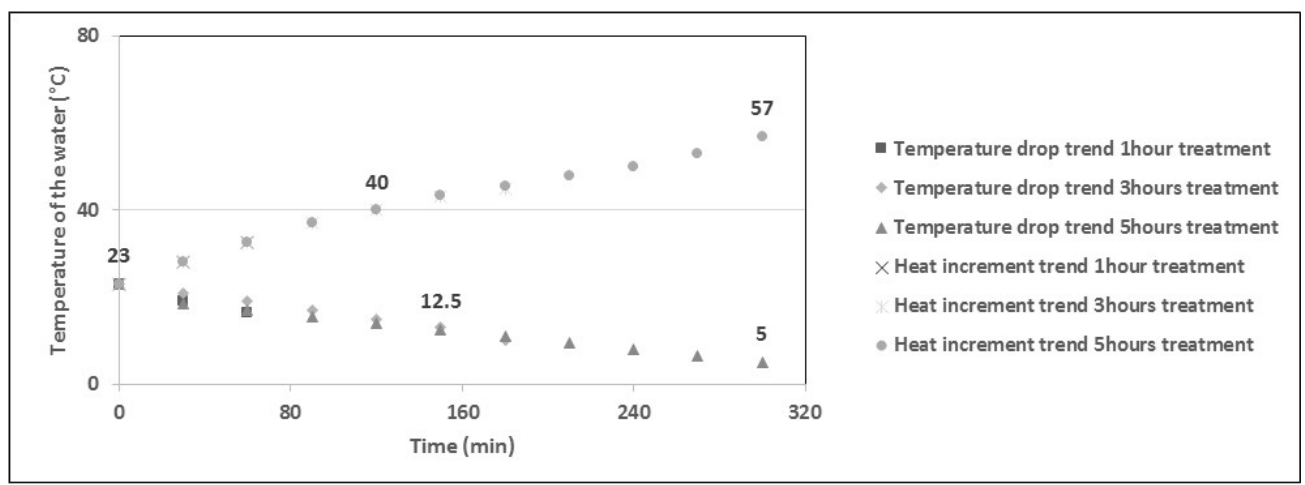

Figure 1. Water bath temperature change in ultrasonic cleaner.

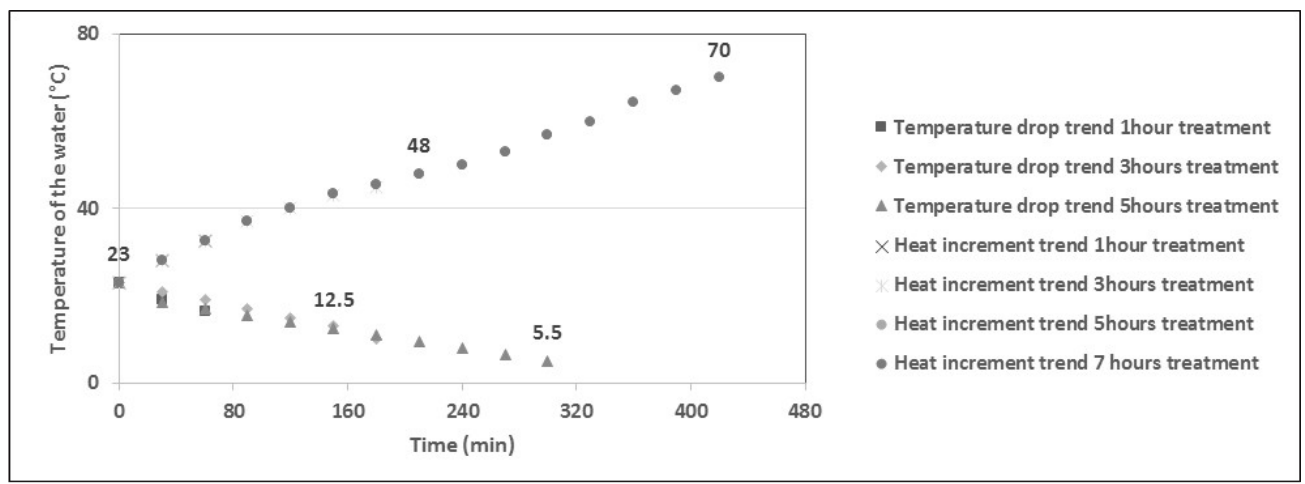

Figure 2. Water bath temperature change with ultrasonic horn.

Time length effect of treatment on nematode mortality was studied using one way analysis of variance (ANOVA) and the Duncan multiple comparison test (Tables 2 and 3). It was established from the data that there was no specific difference on nematode mortality between the $20 \mathrm{KHz} / 200$ watts and $40 \mathrm{KHz} / 320$ watts treatment combinations. The assessment of the results in temperature decrease treatment $\left(\mathrm{T}_{\mathrm{B}}\right)$ revealed that ultrasonic energy had no significant effect on nematode mortality, while, gradually increasing temperature $\left(\mathrm{T}_{\mathrm{A}}\right)$ had a significant effect on nematode mortality. 
Table 2. ANOVA for the effect of the ultrasonic treatment impact on mortality of nematodes at different time of radiation (low level decreasing).

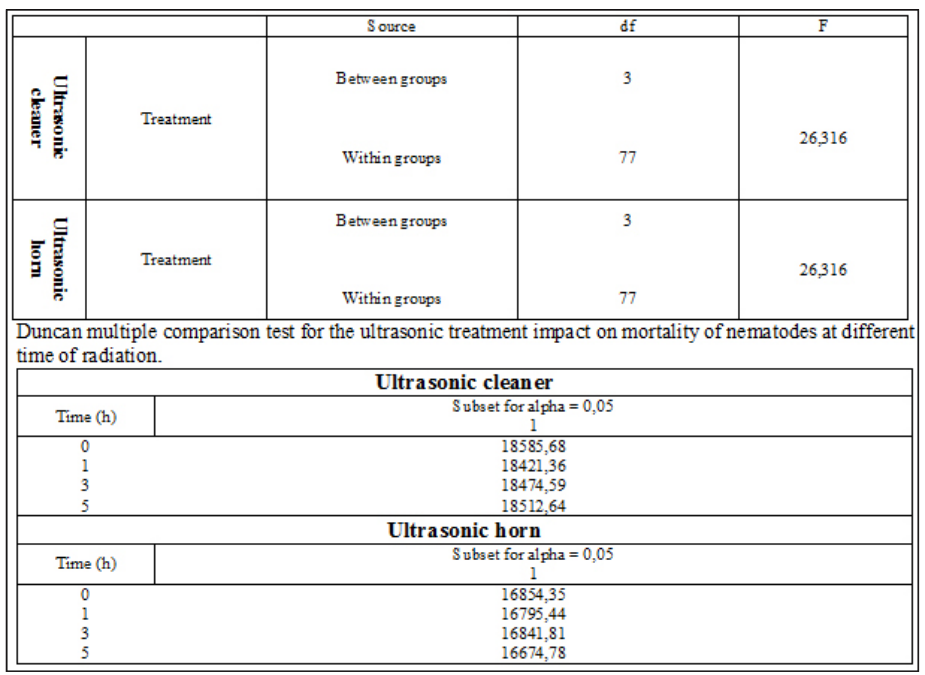

Statistical analysis confirmed that ultrasonic exposure had not a significant effect on nematode mortality for the first few hours of the $\mathrm{T}_{\mathrm{A}}$. However, when approaching the 5-hour treatment point, significant difference on nematode mortality using both instrument setups was observed. This happened after 7 hours of treatment when the temperature rose to near $70^{\circ} \mathrm{C}$; clearly the result of thermal nematode eradication. Consequently, allowing the increase of water temperature under ultrasonic treatment seems effective for complete eradication of the pinewood nematodes in wood.

Table 3. ANOVA for the effect of the ultrasonic treatment impact on mortality of nematodes at different time of radiation (gradually increasing).

\begin{tabular}{|c|c|c|c|c|}
\hline 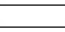 & & Source & dff & $\bar{F}$ \\
\hline 象高 & Treatment & $\begin{array}{l}\text { Between groups } \\
\text { Within groups }\end{array}$ & 77 & 26,316 \\
\hline 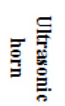 & Treatment & $\begin{array}{l}\text { Between groups } \\
\text { Within groups }\end{array}$ & 4 & 26,221 \\
\hline
\end{tabular}

Duncan multiple comparison test for the ultrasonic treatment impact on mortality of nematodes at different

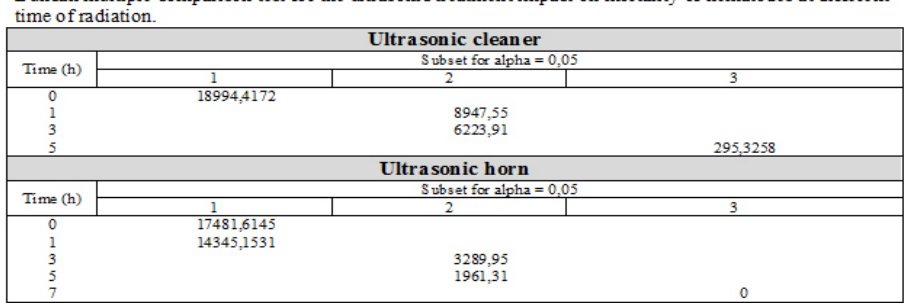

\section{CONCLUSIONS}

The efficiency of ultrasonic treatment as a phytosanitation method for pinewood nematode infected wood was explored in this research. The results showed that ultrasonic energy by itself was not effective in nematode eradication however, combination of ultrasonic energy and produced heat was effective on nematode mortality. 


\section{REFERENCES}

Anonymous. 2002. International standards for phytosanitary measures: guidelines for regulating wood packaging material in international trade, Publ. No. 15. Food and Agriculture Organization of the United Nations, Rome (IT).

Anonymous. 2009a. Wood packaging material enforcement regulations. Germantown, MD: American Lumber Standards Committee, Inc. ALSC WPM program.

Anonymous. 2009b. Regulation of Wood Packaging Material in International Trade. International Standards for Phytosanitary Measures, ISPM-15, Secretariat of International Plant Protection Convention, UN-FAO.

Anonymous. 2009c. International standards for phytosanitary measures: Revision of ISPM No. 15, Regulation of wood packaging material in international trade, Food and Agriculture Organization of the United Nations, Rome (IT).

Bucur, V. 2006. Acoustics of Wood. Springe-Verlag Berlin Heidelberg. pp 1-4.

Crosby, L. 1982. Juices pasteurized ultrasonically. Food Production/ Management, Sept., pp.16.

Ercan, S.; Soysal, Ç. 2013. Use of ultrasound in food preservation. Natural Sci 5(8): 5-13.

Hoover, K.; Uzunovic, A.; Gething, B.; Dale, A.; Leung, K.; Ostiguy, N.; Janowiak, J.J. 2010. Lethal Temperature for Pinewood Nematode, Bursaphelenchusxylophilus, in Infested Wood Using Microwave Energy. J Nematol 42: 101-110.

Kim, B.S.; Kim, O.W.; Kim, D.C.; Kim, G.H. 1999. Development of a surface sterilization system combined with a washing process technology for leafy lettuce. Acta-Horticulture 483: 311-317.

Lazarescu, C.; Dale, A.; Uzunovic, A.; Breuil, C.; Avramidis, S. 2010. Radio frequency heating pasteurization of pine wood nematode (Bursaphelenchus xylophilus) infected wood. Holz als Roh- und Werkstoff 69: 573-578.

Lazarescu, C.; Breuil, C.; Avramidis, S. 2015. Phytosanitation of mountain pine beetle infected lodgepole pine using dielectric fields at radio frequencies. Maderas-Cienc Tecnol 17(2): 221-228.

McClements, D.J. 1995. Advances in the application of ultrasound in food analysis and processing. Trends Food Sci Technol 6: 293-299.

Sala, F.J.; Burgos, J.; Condon, S.; Lopez, P.; Raso, J. 1995. Effect of heat and ultrasound on microorganisms and enzymes. In: Gould, G.W. (Ed.), New Methods of Food Preservation. Blackie Academic \& Professional, London, pp. 176-204.

Salleh-Mack, S.Z.; Roberts, J.S. 2007. Ultrasound pasteurization: the effects of temperature soluble solids organic acids and $\mathrm{pH}$ on the inactivation of Escherichia coli ATCC 25922. Ultrason Sonochem 14: 323-329.

Tanaka, T.; Avramidis, S.; Shida, S. 2010. A preliminary study on ultrasound treatment effect on transvers wood permeability. Maderas-Cienc Tecnol 12(1):3-9.

Taylor, A.; Perchermeier, A.; Young, T.; Zivanovic, L. 2011. A Test of High Intensity Ultrasound for the Phytosanitation of Wood. Forest Prod J 61: 365-366.

Uzunovic, A.; Gething, B.; Coelho, A.; Dale, A.; Janowiak, J.J.; Mack, R.; Hoover, K. 2013. Lethal temperature for pinewood nematode, Bursaphelenchus xylophilus, in infested wood using radio frequency (RF) energy. J Wood Sci 59: 160-170. 